\title{
Pancreatic Intraepithelial Neoplasia-3
}

National Cancer Institute

\section{Source}

National Cancer Institute. Pancreatic Intraepithelial Neoplasia-3. NCI Thesaurus. Code C95432.

A pancreatic epithelial neoplasia characterized by the presence of papillary and rarely flat architectural patterns with formation of cribriform patterns and luminal necrosis. Severe cytological atypia is present. 